\title{
The Influence of Reduction Process on the Iron-Molybdenum Nanoparticles in Modified MCM-41 Silica
}

\author{
Z. Surowiec ${ }^{a, *}$, M. Wiertel $^{a}, \mathrm{~W} . \mathrm{GaC}^{b}$ AND M. BudzYŃSkI ${ }^{a}$ \\ ${ }^{a}$ Institute of Physics, M. Curie-Skłodowska University, pl. M. Curie-Skłodowskiej 1, 20-031 Lublin, Poland \\ ${ }^{b}$ Faculty of Chemistry, M. Curie-Skłodowska University, pl. M. Curie-Skłodowskiej 1, 20-031 Lublin, Poland \\ Iron-molybdenum silica mesoporous materials were obtained by the application of direct hydrothermal method. \\ The influence of high temperature samples reduction in the $\mathrm{H}_{2}$ flow on their structural and magnetic properties was \\ studied. Four samples with different metal contents relative to silica were investigated. The study was carried out \\ by means of X-ray diffraction, ${ }^{57} \mathrm{Fe}$ Mössbauer spectroscopy and the temperature programmed reduction method. \\ With an increasing metals content, primary pores of MCM-41 transformed into the bottle-like pores, and then \\ into the slit-like ones. Reduction and heat treatment caused the $\alpha-\mathrm{Fe}, \mathrm{Fe}_{2} \mathrm{Mo}$, and $\mathrm{Fe}-\mathrm{Mo}$ alloy formation. Iron \\ and molybdenum atoms after being released into the silica matrix, where they were embedded, create clusters \\ or crystallites. It was observed that the high temperature reduction caused partial transformation of highly \\ dispersed $\mathrm{Fe}-\mathrm{Mo}$ oxides species initially embedded in silica walls into crystallites big enough to give magnetic \\ sextet component in the Mössbauer spectra.
}

DOI: $10.12693 /$ APhysPolA.125.846

PACS: 76.80.+y, 78.67.Bf, 78.67.Rb, 75.20.-g

\section{Introduction}

Iron-molybdenum in a form of nanomaterial has been studied widely, because of its application as catalyst and its interesting band and magnetic structures [1]. Iron molybdate, $\mathrm{Fe}_{2}\left(\mathrm{MoO}_{4}\right)_{3}$ with an excess of $\mathrm{MoO}_{3}$ is a typical two-component selective oxidation catalyst [2]. The two components, iron oxide and molybdenum oxide, interact to produce a catalyst which favours the desired product, formaldehyde, rather than the products of total oxidation of methanol, carbon dioxide, and water, or other products like carbon monoxide or dimethyl ether. It is the combination of the two oxides which produces the desired active and selective catalyst [3].

In our previous papers $[4,5]$ we studied iron and ironmolybdenum silica mesoporous materials obtained by the application of direct hydrothermal method. The introduction of different amounts of iron and molybdenum compounds relative to the silica source led to the modification of the structural and surface properties of these materials.

Metals atoms introduced to silica source caused a distortion of the well-ordered MCM-41 silica mesoporous structure. These effects result from the transformation of the regular channels to the worm-like type ones, with more open structures and a formation of macropores. The high iron molybdenum content in silica wall leads to the formation of slit-like pores, which probably result from condensation of silica and deposition of oxides in the lamellar bilayer phases of surfactants. The presence

\footnotetext{
* corresponding author; e-mail:
}

zbigniew.surowiec@umcs.lublin.pl of surfactants and silicon compounds ensured the formation of the fine oxide species.

The aim of the presented studies was preparation of intermetallic iron-molybdenum nanocrystallites by the application of the direct hydrothermal technique and an investigation of their structural and magnetic properties after a reduction process.

\section{Experimental}

Iron-molybdenum silica mesoporous materials were obtained by the application of direct hydrothermal method. Sample preparation details are described in [5].

In order to prepare iron-molybdenum intermetallic systems supported on the mesoporous silica framework, the samples were reduced in the flow of hydrogen at high temperature. To realize this reduction, a sample was placed in a quartz flow reactor. The flow rate of $6 \% \mathrm{H}_{2}-\mathrm{Ar}$ mixture was $30 \mathrm{~cm}^{3} / \mathrm{min}$. The temperature of the reactor was maintained at $1073 \mathrm{~K}$ for $1 \mathrm{~h}$. Then the sample was cooled to the room temperature, flushed with helium $\left(0.5 \mathrm{~h}\right.$ at a flow of $\left.30 \mathrm{~cm}^{3} / \mathrm{min}\right)$ and finally passivated in the flow of $5 \% \mathrm{O}_{2}-\mathrm{He}$ mixture. This procedure allowed for the formation of the thin oxide layer on the surface of the metal crystallites and prevented deep oxidation of the species.

The molar ratio of iron to molybdenum $\mathrm{Fe} / \mathrm{Mo}$ was the same in all samples and equal to 2:3. The introduced amounts of iron were varied, in order to obtain samples containing: $3 \mathrm{wt} \% \mathrm{Fe}$ (denoted as RED $\mathrm{Fe}-\mathrm{Mo}(\mathrm{A})-\mathrm{Si}$ ), $6.5 \mathrm{wt} \% \mathrm{Fe}$ (denoted as RED Fe-Mo(B)-Si), $12.5 \mathrm{wt} \% \mathrm{Fe}$ (denoted as RED Fe-Mo(C)-Si) and $24.3 \mathrm{wt} \% \mathrm{Fe}$ (denoted as RED Fe-Mo(D)-Si).

Phase analysis was carried out by means of X-ray powder diffraction using an X-ray Empyrean diffractometer with $\mathrm{Cu} K_{\alpha}$ radiation. The Mössbauer spectra were measured in a conventional transmission geometry with a 
${ }^{57} \mathrm{Co}(\mathrm{Rh})$ as a source. The samples were held at room (RT) and the liquid nitrogen (LN) temperatures.

\section{Results and discussion}

The reduction process of $\mathrm{Fe}-\mathrm{Mo}-\mathrm{O}$ species with different metals relative to silica template ratio were studied by means of the temperature programmed reduction (TPR). Figure 1 shows the TPR profiles of a series ironmolybdenum oxide modified silica systems. The rate of hydrogen consumption corresponding to maxima of TPR curves increases with an increase of iron and molybdenum contents. The TPR patterns measured for the samples with a larger metals content are more complicated and contain more reduction peaks.

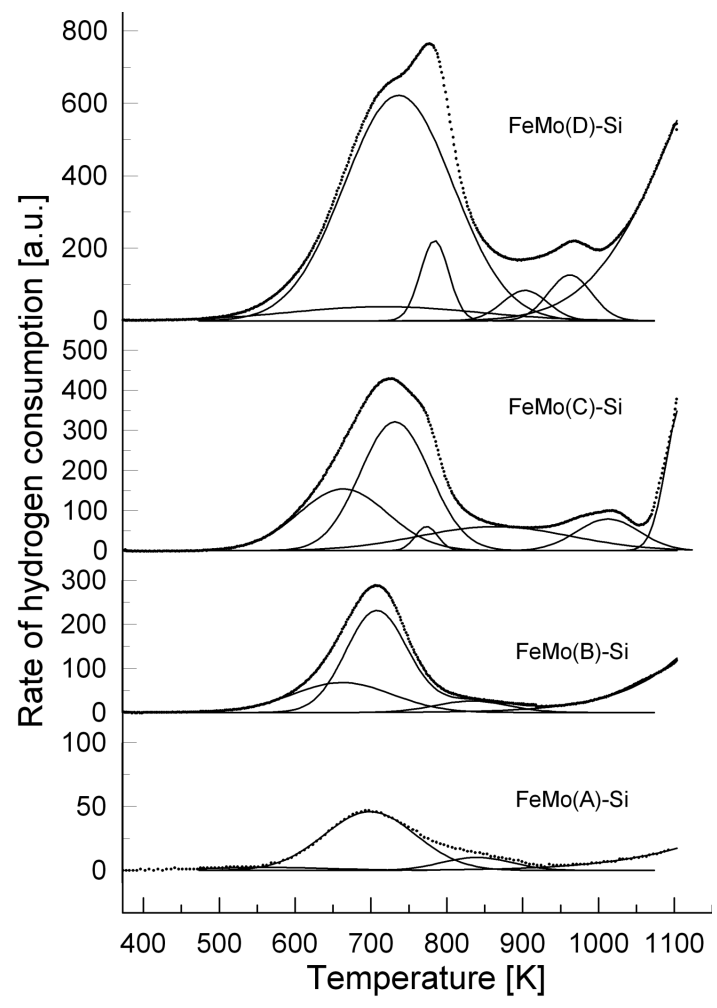

Fig. 1. TPR profile. The points are experimental data, the lines are numerical fit. Explanations are to be seen in the text.

The maximum on the TPR curves at the lowest temperature is usually anticipated as the reduction of free $\mathrm{Fe}_{3} \mathrm{O}_{4}$ accordingly to the reaction equation

$$
\mathrm{Fe}_{3} \mathrm{O}_{4}+\mathrm{H}_{2} \rightarrow 3 \mathrm{FeO}+\mathrm{H}_{2} \mathrm{O} \text {. }
$$

The reduction of $\mathrm{FeO}$ usually occurs at the temperatures above $950 \mathrm{~K}$ accordingly to the equation

$\mathrm{FeO}+\mathrm{H}_{2} \rightarrow \mathrm{Fe}+\mathrm{H}_{2} \mathrm{O}$.

The interpretation of TPR curves for the ironmolybdenum systems is even more complicated due to the fact that the materials are composed not only from the individual iron and molybdenum oxide phases, but they also exhibit mutual interactions and may form chemical compounds. For the $\mathrm{Fe}-\mathrm{Mo}-\mathrm{O}$ mixed oxides $\mathrm{MoO}_{3}$ and $\mathrm{Fe}_{2}\left(\mathrm{MoO}_{4}\right)_{3}$ occur in the sample [6].

The reduction of $\mathrm{MoO}_{3}$ to $\mathrm{MoO}_{2}$ and $\mathrm{Fe}_{2}\left(\mathrm{MoO}_{4}\right)_{3}$ to $2 \beta-\mathrm{FeMoO}_{4}$ takes place at temperature in the range from $855 \mathrm{~K}$ to $1000 \mathrm{~K}$ as follows:

$$
\begin{aligned}
& \mathrm{MoO}_{3}+\mathrm{H}_{2} \rightarrow \mathrm{MoO}_{2}+\mathrm{H}_{2} \mathrm{O} \\
& \mathrm{Fe}_{2}\left(\mathrm{MoO}_{4}\right)_{3}+\mathrm{H}_{2} \rightarrow 2 \beta-\mathrm{FeMoO}_{4}+\mathrm{MoO}_{3}+\mathrm{H}_{2} \mathrm{O} \text {. }
\end{aligned}
$$

Molybdenum oxide $\mathrm{MoO}_{2}$ is then reduced to the metallic molybdenum at even higher temperature. $\beta$-FeMoO ${ }_{4}$ is successively reduced, through $\mathrm{FeMoO}_{3}, \mathrm{Fe}_{2} \mathrm{Mo}_{3} \mathrm{O}_{8}$, and $\mathrm{Fe}_{3} \mathrm{O}_{4}$, and oxides on the lower oxidation states

$$
\begin{aligned}
& \mathrm{MoO}_{2}+2 \mathrm{H}_{2} \rightarrow \mathrm{Mo}+2 \mathrm{H}_{2} \mathrm{O}, \\
& \mathrm{Fe}_{2} \mathrm{Mo}_{3} \mathrm{O}_{8}+2 \mathrm{H}_{2} \rightarrow 2 \mathrm{Fe}+3 \mathrm{MoO}_{2}+2 \mathrm{H}_{2} \mathrm{O} .
\end{aligned}
$$

We attribute the last TPR maximum starting at $1020 \mathrm{~K}$ to the reduction of $\mathrm{Fe}_{2} \mathrm{MoO}_{4}$. The chemical reaction for the reduction of $\mathrm{Fe}_{2} \mathrm{MoO}_{4}$ by hydrogen gas can be written as follows:

$$
\mathrm{Fe}_{2} \mathrm{MoO}_{4}+4 \mathrm{H}_{2} \rightarrow \mathrm{Fe}_{2} \mathrm{Mo}+4 \mathrm{H}_{2} \mathrm{O} \text {. }
$$

Finally, the mixture of metallic iron, molybdenum and intermetalic compounds $\mathrm{Fe}_{2} \mathrm{Mo}$ are formed [7]. In the case of silica supported systems, the high reduction temperature may also facilitate the formation of different iron silicalites of low reducibility.

In the XRD patterns Bragg's reflections are not observed for all the samples studied before reduction. Only an amorphic halo resulting from silica is visible. These results indicate that strongly dispersed iron and molybdenum oxide species, with the size below detection limit of the X-ray diffraction method occur.

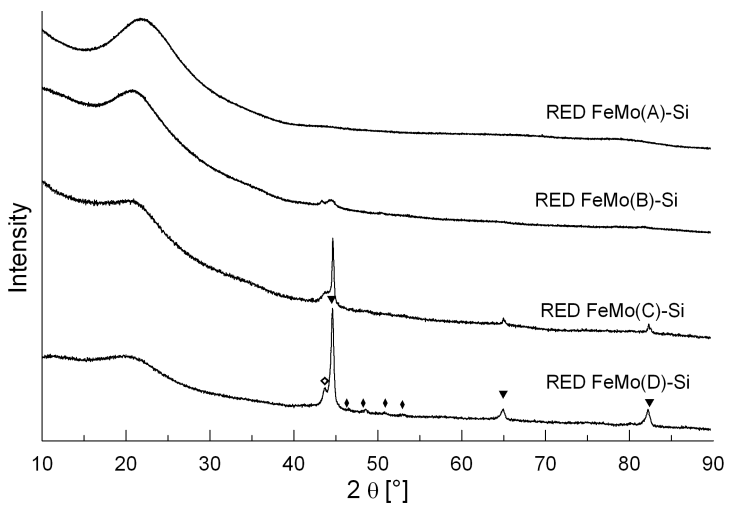

Fig. 2. The XRD diffraction patterns of samples $\mathrm{FeMo}(\mathrm{A})-\mathrm{Si}, \quad \mathrm{FeMo}(\mathrm{B})-\mathrm{Si}, \quad \mathrm{FeMo}(\mathrm{C})-\mathrm{Si}, \quad$ and $\mathrm{FeMo}(\mathrm{D})-\mathrm{Si}$ after reduction process.

The XRD patterns for samples after reduction treatment are shown in Fig. 2. For the first sample denoted RED FeMo(A)-Si with the least metal content, the pattern is similar to that for samples before reduction treatment. The reflections from crystal structure are not observed. The wide halo outstretched between $15^{\circ}$ and $30^{\circ}$ results from the amorphous silica support. In the next pattern recorded for the RED FeMo(B)-Si sample slight Bragg reflections can be observed at angles $2 \theta$ 
equal to $43.3^{\circ}$ and $44.4^{\circ}$, respectively. For the samples with high metals content, the reflections from crystallographic structure appear. As a result of reduction and heat treatment, the $\alpha-\mathrm{Fe}, \mathrm{Fe}_{2} \mathrm{Mo}$, and $\mathrm{Fe}-\mathrm{Mo}$ alloy were formed. Iron and molybdenum atoms embedded into the silica matrix were released from it and they create clusters or crystallites.

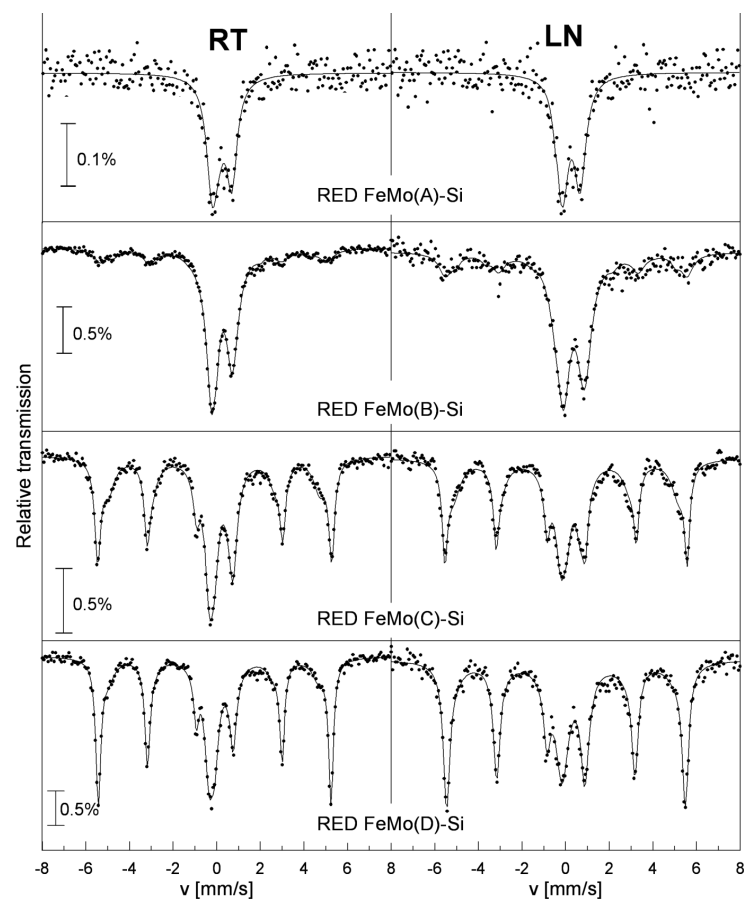

Fig. 3. $\quad{ }^{57} \mathrm{Fe}$ Mössbauer spectra measured at RT (left part) and at LN (right part) for different metal content in sample.

The Mössbauer spectra of the reduced sample measured at RT and LN are shown in Fig. 3. The spectrum for the RED FeMo(A)-Si sample consists of two nonmagnetic components. The first one coming from nanocrystallites in superparamagnetic state and the second one is related to $\mathrm{Fe}_{2}$ Mo Laves phase. The hyperfine interaction parameters determined for the $\mathrm{Fe}_{2} \mathrm{Mo}$ doublet (summarised in Table) correspond to those obtained in $[8,9]$. The Mössbauer patterns of the samples with larger metal loading are composed of two additional Zeeman sextets. The component with larger hyperfine magnetic field could be ascribed to $\alpha$-Fe. The second magnetic component comes from iron-rich Fe-Mo alloy. The presence of these phases is also confirmed by XRD data.

With increase of metal content in silica matrix, the contribution of a superparamagnetic component decreases. This shows that the nanocrystalline oxide species combine with each other during the reduction process at the high temperature $\left(800^{\circ} \mathrm{C}\right)$. The binding of disperged nanocrystallites in mesoporous silica is different for different kind of modified MCM-41 silica support. In the sample RED FeMo(A)-Si, the porous structure of the materials modified with the small amount of iron
TABLE

Values of hyperfine parameters IS, QS, $B_{\mathrm{hf}}$, and $A-$ subspectra area.

\begin{tabular}{|c|c|c|c|c|c|c|}
\hline Samples & $T$ & Component & $\begin{array}{c}\mathrm{IS}^{* a} \\
{[\mathrm{~mm} / \mathrm{s}]}\end{array}$ & $\begin{array}{c}\mathrm{QS}^{*} \\
{[\mathrm{~mm} / \mathrm{s}]}\end{array}$ & $\begin{array}{l}B_{\mathrm{hf}} \\
{[\mathrm{T}]}\end{array}$ & $\begin{array}{c}A \\
{[\%]}\end{array}$ \\
\hline \multirow{4}{*}{$\begin{array}{c}\text { RED } \\
\text { FeMo(A)-Si }\end{array}$} & \multirow{2}{*}{ RT } & SPM & 0.32 & 0.78 & - & 92 \\
\hline & & $\mathrm{Fe}_{2} \mathrm{Mo}$ & -0.01 & 0.24 & - & 8 \\
\hline & \multirow{2}{*}{ LN } & SPM & 0.46 & 0.80 & - & 87 \\
\hline & & $\mathrm{Fe}_{2} \mathrm{Mo}$ & 0.12 & 0.24 & - & 13 \\
\hline \multirow{8}{*}{$\begin{array}{c}\text { RED } \\
\text { FeMo(B)-Si }\end{array}$} & \multirow{4}{*}{ RT } & SPM & 0.32 & 0.96 & - & 65 \\
\hline & & $\mathrm{Fe}_{2} \mathrm{Mo}$ & -0.06 & 0.22 & - & 11 \\
\hline & & $\mathrm{Fe}-\mathrm{Mo}$ & -0.14 & -0.03 & 28.0 & 6 \\
\hline & & $\mathrm{Fe}$ & 0.0 & 0.01 & 32.3 & 17 \\
\hline & \multirow{4}{*}{ LN } & SPM & 0.45 & 0.98 & - & 60 \\
\hline & & $\mathrm{Fe}_{2} \mathrm{Mo}$ & 0.16 & 0.24 & - & 6 \\
\hline & & $\mathrm{Fe}-\mathrm{Mo}$ & 0.12 & -0.04 & 29.3 & 8 \\
\hline & & $\mathrm{Fe}$ & 0.08 & 0.03 & 34.1 & 24 \\
\hline \multirow{8}{*}{$\begin{array}{c}\text { RED } \\
\text { FeMo(C)-Si }\end{array}$} & \multirow{4}{*}{ RT } & SPM & 0.29 & 1.00 & - & 23 \\
\hline & & $\mathrm{Fe}_{2} \mathrm{Mo}$ & -0.13 & 0.26 & - & 14 \\
\hline & & $\mathrm{Fe}-\mathrm{Mo}$ & -0.12 & -0.03 & 30.1 & 26 \\
\hline & & $\mathrm{Fe}$ & -0.01 & 0.01 & 33.3 & 38 \\
\hline & \multirow{4}{*}{$\mathrm{LN}$} & SPM & 0.29 & 1.00 & - & 17 \\
\hline & & $\mathrm{Fe}_{2} \mathrm{Mo}$ & 0.04 & 0.28 & - & 12 \\
\hline & & $\mathrm{Fe}-\mathrm{Mo}$ & 0.07 & -0.05 & 32.1 & 30 \\
\hline & & $\mathrm{Fe}$ & 0.11 & 0.01 & 34.5 & 41 \\
\hline \multirow{8}{*}{$\begin{array}{c}\text { RED } \\
\text { FeMo(D)-Si }\end{array}$} & \multirow{4}{*}{ RT } & SPM & 0.31 & 1.05 & - & 13 \\
\hline & & $\mathrm{Fe}_{2} \mathrm{Mo}$ & -014 & 0.27 & - & 19 \\
\hline & & $\mathrm{Fe}-\mathrm{Mo}$ & -0.10 & -0.06 & 30.0 & 18 \\
\hline & & $\mathrm{Fe}$ & -0.01 & 0.00 & 33.2 & 50 \\
\hline & \multirow{4}{*}{$\mathrm{LN}$} & SPM & 0.46 & 1.04 & - & 10 \\
\hline & & $\mathrm{Fe}_{2} \mathrm{Mo}$ & -0.09 & 0.22 & - & 15 \\
\hline & & $\mathrm{Fe}-\mathrm{Mo}$ & 0.01 & -0.07 & 31.9 & 22 \\
\hline & & $\mathrm{Fe}$ & 0.01 & 0.00 & 34.0 & 53 \\
\hline
\end{tabular}

${ }^{*}$ Uncertainty estimated from the fitting procedure is equal to $\pm 0.01 \mathrm{~mm} / \mathrm{s}$.

${ }^{a}$ Relative to the $\alpha$-Fe foil at room temperature.

and molybdenum is similar to the MCM-41 pure silica mesoporous supports.

The crystallites can be created only in the narrow channels of the support. The average size of pores is equal to $3.5 \mathrm{~nm}$ [5]. An increase of metal loading (sample RED FeMo(B)-Si) induces a distortion of the well-ordered structure and a transformation of the regular channels to the bottle-like type ones with more open structures and the formation of macropores. For the high content of modifying metals in the samples RED $\mathrm{FeMo}(\mathrm{C})-\mathrm{Si}$ and the RED FeMo(D)-Si, the framework has slit-like pores. In the modified structure of the mesoporous silica, there is a large enough space to create larger crystallites.

The contributions of all phases occurring in the investigated samples are presented in Fig. 4. The occurrence of the superparamagnetic phase is correlated to the shape and size of pores in mesoporous silica support. The 


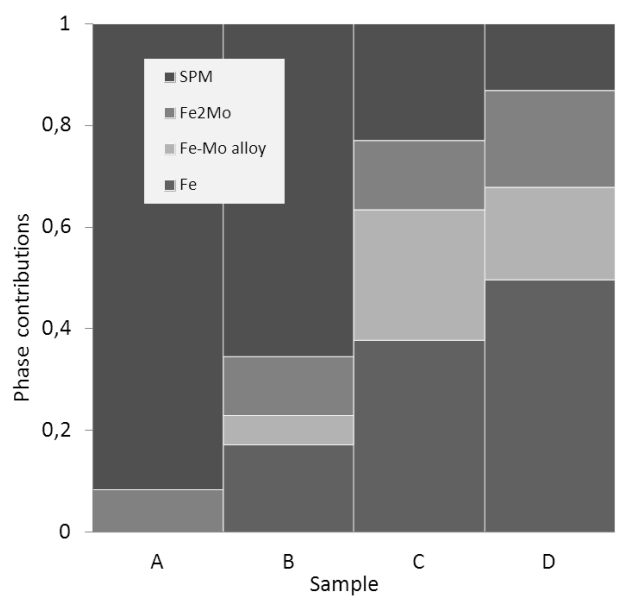

Fig. 4. The phase contributions for the samples with different $\mathrm{Fe}-\mathrm{Mo}$ content in silica template after reduction derived from room temperature MS spectra.

smaller the pore volume is, the more nanoparticles are in the silicate.

\section{Conclusions}

The investigated samples were reduced in temperatures up to $800{ }^{\circ} \mathrm{C}$ in $6 \% \mathrm{H}_{2} / \mathrm{Ar}$ atmosphere. In the reduction process, iron-molybdenum oxides species were transformed to metallic and intermetallic phases. In the samples with low $\mathrm{Fe}$ and Mo content ( $\mathrm{A}$ and $\mathrm{B}$ ), the formed phases remained highly dispersed in silica matrix. The Mössbauer measurements indicated the superparamagnetic behaviour of the $\mathrm{Fe}-\mathrm{Mo}$ nanocrystallites located in silica pores. At the higher metal content above $16.7 \mathrm{wt} \%$ nanocrystallites aggregate to create bigger crystals. The three phases: pure $\mathrm{Fe}, \mathrm{Fe}_{2} \mathrm{Mo}$, and $\mathrm{Fe}$ rich $\mathrm{Fe}-\mathrm{Mo}$ alloy are indentified both by means of XRD and MS methods.

\section{References}

[1] A. Błachowski, K. Ruebenbauer, J. Żukrowski, J. Przewoźnik, J. Alloys Comp. 482, 23 (2009).

[2] J.J. Uhlrich, J. Sainio, Y. Lei, D. Edwards, R. Davies, M. Bowker, S. Shaikhutdinov, H.-J. Freund, Surf. Sci. 605, 1550 (2011).

[3] T.H. Kim, B. Ramachandra, J.S. Choi, M.B. Saidutta, K.Y. Choo, S.D. Song, Y.W. Rhee, Catal. Lett. 98, 161 (2004).

[4] M. Wiertel, Z. Surowiec, M. Budzyński, W. Gac, Nukleonika 58, 245 (2013).

[5] Z. Surowiec, M. Wiertel, A. Marynowska, W. Gac, W. Zawadzki, Nukleonika 58, 137 (2013).

[6] H. Zhang, Z. Li, X. Fu, J.P. Huang, Y. Zhang, J. Mol. Catal. 3, 139 (1998).

[7] R. Morales, D.U. Sichen, S. Seetharaman, Metall. Mater. Trans. B 34, 661 (2003).

[8] H. Zhang, J. Shen, X. Ge, J. Solid State Chem. 117, 127 (1999).

[9] H.L. Marcus, M.E. Fine, L.H. Schwartz, J. Appl. Phys. 38, 4750 (1967). 